\title{
Woolenization of Jute Fibre
}

\author{
Rony Mia \\ Lecturer, Department of Textile Engineering (Wet Processing) \\ National Institute of Textile Engineering \& Research (NITER) \\ Md. Ariful Islam \\ Production Officer (Yarn Dyeing) \\ Mega Yarn Dyeing Mills Ltd \\ Bulbul Ahmed \\ Executive Officer (Yarn Dyeing) \\ Hamid Fabrics Ltd \\ Jalal Ibn Amin Mojumdar \\ Executive Officer (Woven Dyeing) \\ Hamid Fabrics Ltd
}

Doi: 10.19044/esj.2017.v13n30p314 URL:http://dx.doi.org/10.19044/esj.2017.v13n30p314

\begin{abstract}
Once upon a time, Jute was called the golden fibre of Bangladesh. Due to some problems and growth of modern technology, the market share of jute has decreased. In this paper, the effect of Woolenization of jute fibre was described. It also shows how the physical and chemical properties of jute have been changed by alkali-treatment as well as its structure. It was demonstrated that this kind of treatment leads to several changes in its structure which has turned to a near wool structure. These works are done by different concentrations of different alkalis. Finally, $15 \% \mathrm{NaOH}$ treatment of jute show maximum woolenized properties where we obtain softened and swollen jute. Conclusively, we have made some other products from woolenized jute fibres such that if introduced into our world market, it can increase the market share of jute fibre.
\end{abstract}

Keywords: Jute, Woolenization, Alkali-treatment, $\mathrm{NaOH}$

\section{Introduction}

Jute is a golden fibre in our country. Recently, its demand has reduced and it cannot be utilized properly in the world. Hence, the golden fibre has deteriorated into zero fibre. However, some research centers are trying their best to modify jute fibre, while different universities and institutions are trying to make contemporary wool fibre by improving their 
thesis. Jute fibre is one of the world's most important best natural fibres. It is a bast fibre which is obtained from two species such as white and tossa jute. It has high specific properties, low density, less abrasive behavior, good dimensional stability, and is harmlessness. Jute textile is a low cost ecofriendly product and is abundantly available, easy to transport, and has superior drapability and moisture retention capacity. It is widely being used as a natural option for plant mulching and rural road pavement construction. Biodegradable and low priced jute products are increasing day by day (Atkinson A. R.R).

Wool fibre is the most important natural fibre in the world. Animal hair consists of complex proteins. The hair of sheep and goats is particularly important for textile wool. Thus, animal fibre has outstanding importance. It comes from fibrous covering of the sheep, goat, camel etc. One of the first things we meet on entering the world is wool. Woolies are worn by babies because they are warm and airy. Wool cloths are healthy and hard wearing. Due to crimps, each fibre stands away from its neighbors and is used in suits and dress materials, blankets, carpets, jackets etc. So, wool is widely used in the world as textile products. In our growing world, wool fibre is very much needed (Cook J. G). Woolenization of jute is the process of treating the jute fiber with strong alkali to improve severely the appearance, grip, and blends of the jute fibre. Profound changes occur in its physical structure such as lateral swelling, together with considerable shrinkage in lengths. This occurs because the fiber is soft to touch and it develops a high degree of crimp or waviness. The crimp gives a wool-like appearance to the fiber and the resultant fiber is termed as woolenized jute fibre (Menachem Lewin, 1998).

\section{Jute Fibre and Its Properties}

Jute: Jute is a long, soft, shiny vegetable fibre that can be spun into coarse strong threads. It is produced from plants in the genus Corchorus. Jute is one of the most affordable natural fibres. It falls into the bast fibre category (fibre collected from bast or skin of the plant) along with kenaf, industrial hemp, flax, ramie etc. The industrial term for jute fibre is raw jute. The fibres are off-white to brown, and are 1-4 meters (3-13 feet) long. Jute is also called "the golden fibre" because of its colour and high cash value. 


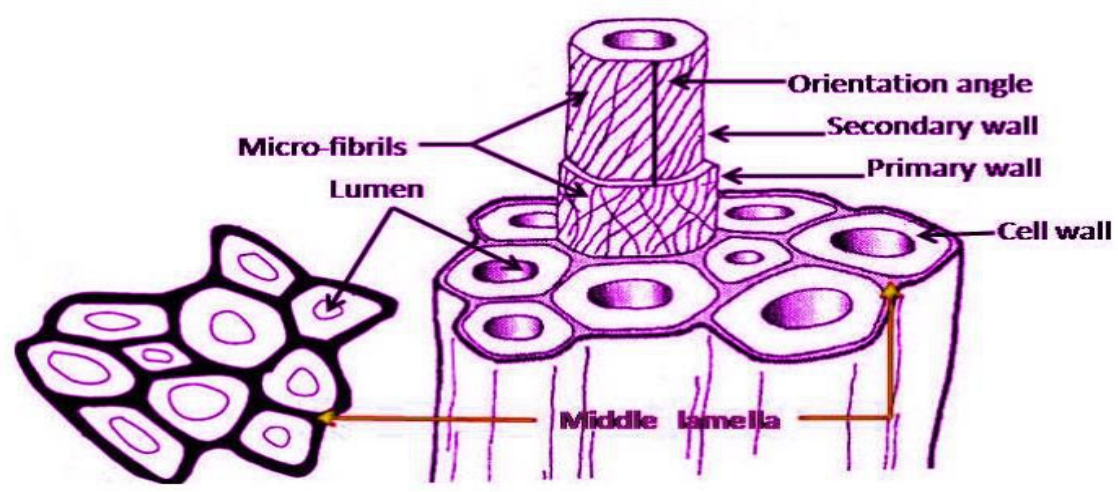

Figure 1. Cross-Sectional View and Micro-Structure of Jute fibre

\section{Wool Fibre and Its Properties}

Wool: Wool is an animal fibre and the animal hair consists of complex protein. This fibre comes from the fibrous covering of the sheep, goat, camel etc. For thousands of years, wool has been used for clothing and in other textiles by different tribes and nations around the world. Till date, wool fibre has great importance because of its unique natural properties that are absent in other natural and synthetic fibre.

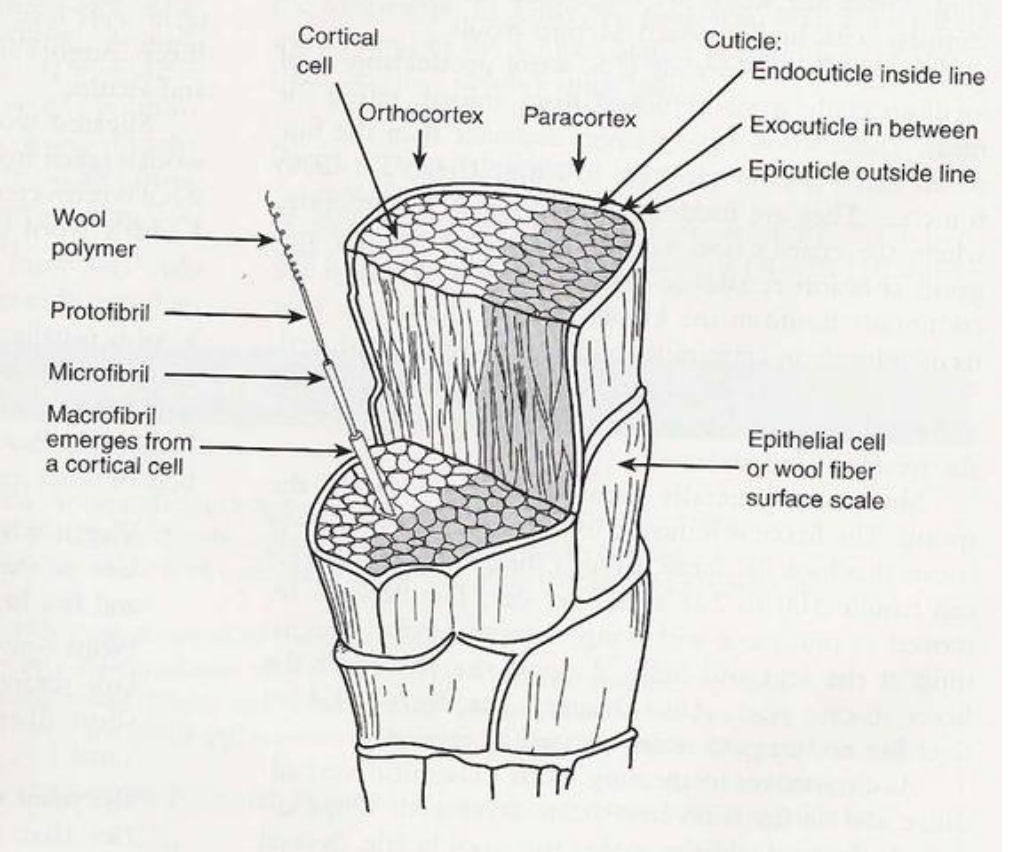

Figure 2. Morphological Structure of Wool fiber 
Woolenization (Nazmina Chowdhury, 2009)

Woolenization is a process that severely improves the appearance, handle, and blend of jute fibers. Through this process, jute fiber is treated with strong alkali, and remarkable changes occur in its physical structure. Also, lateral swelling occurs together with considerable shrinkage in length. As a result of this, the fiber is soft to touch and develops a high degree of crimp or waviness. The crimp gives a "wool like" appearance to the fiber and the resultant fiber is termed as modified jute.

\section{Some Important Properties Considered for Woolenization of Jute Fibre}

Strength: Strength is a property of textile fiber. The quality of being physically strong is the ability to resist being moved or broken by a force.

Drape: Drape means covering by cloth. It is to decorate or cover with folds of cloth and to arrange or hang in flowing lines.

Swelling: Swelling may be defined as an increase in volume upon absorption of liquid by a solid surface.

Stiffness: Stiffness is the property of textile fibers. It is the rigidity of an object - the extent at which it resists deformation in response to an applied force. The complementary concept is flexibility or pliability: the more flexible an object is, the less stiff it becomes.

\section{Literature Review}

In the year 1981, Latifa Binte Lutfar, the Scientific Officer of Physics Department (also named Physics and Testing Division, BJRI.), worked on the effect of the crimp characteristics of jute treated with caustic alkali/liquid ammonia. She reported a decrease in diameter of the fiber and increase in crimp.

In 1989, Ghosh and Dutta found that there is a possibility of improving the mechanical properties of jute composites by alkali treatment of fibers (Ghosh \& Dutta, 1989).

In 1996, Basu reported the effect of ambient temperature bleaching of jute fibre with hydrogen peroxide on yarn properties and dyeing behavior (Bassu, 1996).

In 1999, the English chemist, Andrzej K. Bledzki and Jochen Gassan, found that there is a possibility of improving drapability of jute composites by alkali treatment of fibers (Andrzej \& Jochen, 1999).

In 2001, Dipa Ray and B. K. Sarkar reported in the bulletin of material science that different concentrations of $\mathrm{NaOH}$ have different effects (Dipa Ray \& Sarkar, 2001).

In 2003, P.k Ray and B.k Das worked on the partial mercerization and crimp development in jute fibre and reported some crimp development in jute fiber (Ray \& Das, 2003). 
In 2008, Indian researcher, AK Samanta and P Ghosh, enhanced the spinnability of jute by treating with glycol and acrylamide (Samanta \& Ghosh, 2008).

In 2009, Chowdhury and Azd, tried to find the chemical effect of physio-mechanical properties of jute \& jute-synthetic blended (80//20) yarns $\&$ they reported more quality ratio in woolenized yarn other than grey, bleached, dyed \& softened yarn but this was blended jute yarn (Chowdhury \& Azd, 2009).

In 2010, Sudipta Ray worked on the application of jute fibre and he reported the effect of different concentrations of alkalis on jute and its intended purpose (Ray, 2010).

In 2010, Anup K. Nandi, Utpal Banerjee, and Debkumar Biswas, the researchers of Indian Jute Industries Research Association (IJIRA), reported that when jute is blended with other fibres, the physical and aesthetics properties of jute fabric is improved (Anup K. Nandi, Utpal Banerjee, \& Debkumar Biswas, 2010).

The members of Bio resource committee in 2012, by using the Weibull distribution model, gave the result that low concentration alkali treatment enhances the mechanical properties of jute fibre and hydrophobicity of jute fibre increases significantly by mild alkali treatment.

In 2013, Bijay Dhakal worked on the effect of loading and orientation of jute fibre and he reported how the structure of jute fiber is changed (Bijay Dhakal, 2013).

\section{Materials and Method}

\section{Materials}

1. The purified jute yarns which are free from any waxing material.

2. The chemical agents used for this processes are:

- $\quad$ Caustic Soda

- Basic dyes

- Salt

- $\quad$ Acetic acid

- $\quad$ Sodium acetate

- Soda ash

- $\quad$ Stabilizer

- Hydrogen peroxide

- $\quad$ Wetting agent

- $\quad$ Sequestering agent

- $\quad$ Leveling agent, etc.

3. For producing finished products, Hand knitting devices are used 


\section{Methods}

The Overall process sequence of Woolenization of Jute fibers are discussed below:

\section{Working Flowchart}

\section{Scouring \& Bleaching}

Woolenizing

\section{Dyeing}

\section{Softening}

\section{Knitting}

Finished Products

\section{Scouring and Bleaching}

Firstly, the grey jute fibers are taken. Then impurities such as fat, oil, wax etc. and natural coloring matters of jute fiber is removed. Also, the preparation of jute fibers in a uniform manner for woolenization, scouring, and bleaching is done. Soda ash and Hydrogen peroxide are used to complete the scouring and bleaching process of jute yarn.

\section{Recipe}

Soda ash - 4 gm/L

Hydrogen peroxide $-1 \mathrm{gm} / \mathrm{L}$

Stabilizer $-0.1 \mathrm{gm} / \mathrm{L}$

Wetting agent (Lisapol) $-4 \mathrm{gm} . / \mathrm{L}$.

M:L - 1:10

Temp. X Time $-80^{\circ} \mathrm{C} \times 60 \mathrm{~min}$.

\section{Woolenizing}

After the scouring and bleaching of jute fiber, woolenization is done. It is done by different concentrations of different alkaline solutions for severely improving the appearance and handle of jute fiber. It also affects the yarn and remarkable changes occur in its physical structure. Lateral swelling occurs together with considerable shrinkage in length and warmness on its 
surface. As a result, the yarn is softened to touch and develop a high degree of crimp or waviness. The crimp gives a "Wool Like" appearance to the yarn and the resulted yarn is termed as "Woolenized Yarn". Therefore, this process is carried out using different recipes.

\section{Recipe}

Different Concentrations of Alkaline Solutions

Used solutions are:

1. $5 \% \mathrm{NaOH}$.

2. $10 \% \mathrm{NaOH}$.

3. $15 \% \mathrm{NaOH}$.

4. $20 \% \mathrm{NaOH}$.

5. $10 \% \mathrm{Na}_{2} \mathrm{CO}_{3}$.

6. Ammonia.

Temp X Time- $60^{\circ} \mathrm{C} \times 30 \mathrm{~min}$.

For Acid wash:

\section{Dyeing}

Acetic Acid- 2gm/L

It is the process of jute materials coloration. After woolenizing the jute yarn, dyeing is done. The dyeing process is done in an open bath with suitable selected dye stuffs based on the use of end-products. It also changes the appearance of the jute fiber. Here, we used Basic dye with auxiliaries.

\section{Recipe}

Basic Dye- 2\% owf.

Acetic Acid- 2gm/L

Sodium acetate- $1 \mathrm{gm} / \mathrm{L}$

Wetting agent- $1 \mathrm{gm} / \mathrm{L}$

Sequestering agent $-1 \mathrm{gm} / \mathrm{L}$

M:L- 1:10

Temp. X Time $-80^{\circ} \mathrm{C} \times 60 \mathrm{~min}$.

\section{Softening}

Softening is done to improve the feel of the properties on the hand and is applied to remove the harsh surface from the jute yarn. It makes the jute yarn soft to touch nearly as wool. It is done by using cationic softener.

\section{Recipe}

Cationic Softener $-4 \mathrm{gm} / \mathrm{L}$.

\section{For Acid Wash}

Acetic Acid - 1gm/L 


\section{Knitting}

Knitting is the process of creating or producing fabric by transferring continuous yarn into interlocking loops where each raw of loops hang from the previous one. To produce a fabric from woolenized jute yarn, we used hand knitting devices. Hand knitting is a form of knitting, in which the knitted fabric is produced by hand using needles.

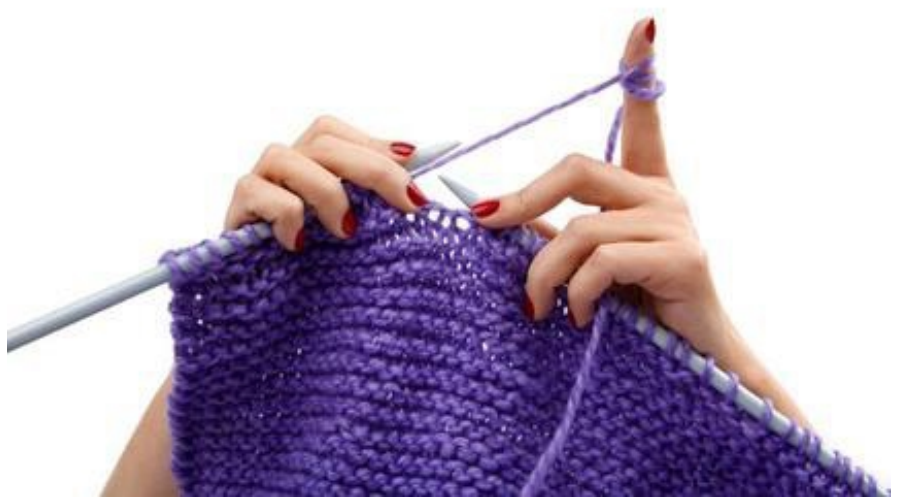

Figure 3. Producing hand knitted product from woolenized jute yarn

\section{Finished Products}

After producing hand knitted fabrics, then we prepared some finished products such as bags muffler etc.

\section{Result and Discussion \\ Scouring and Bleaching}

By scouring and bleaching, we get scoured and bleached jute yarn which is free from waxes and natural coloring material. In addition, the grey jute yarn is converted into scoured and bleached yarn.

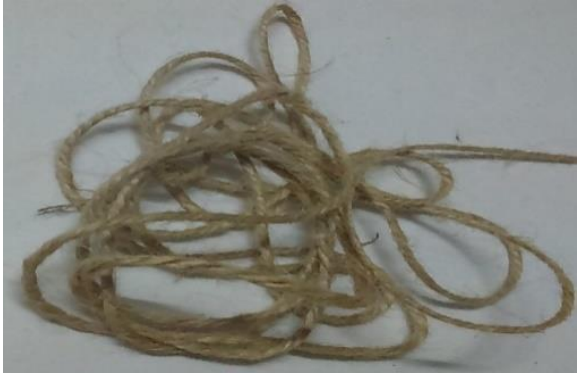

Grey Jute Yarn

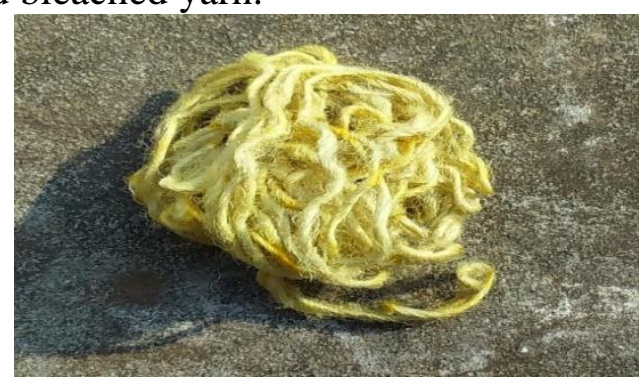

Scoured \& Bleached Jute Yarn

Figure 4. Grey Jute yarn converted into scoured and bleached jute yarn 


\section{Woolenization}

In woolenization process, the results show that the structure of jute fiber is changed where the lateral swelling occurred. The crimp behavior gives wool like appearance. Also, the warmness of jute fiber is increased and it mainly gets good hand feel properties like wool.

We got different woolenized yarn by using different concentrations of different alkaline solutions. A complete woolenization is not done for all solutions because the swelling behavior of jute is increased. In addition, we got more swelling effect on $20 \% \mathrm{NaOH}$ solution. This has good hand feel properties but the strength of this jute was very poor. On one other hand, ammonia, $5 \% \mathrm{NaOH}, 10 \% \mathrm{NaOH}$, and $10 \% \mathrm{Na}_{2} \mathrm{CO}_{3}$ solution treated jute yarn gave a lower swelling effect. On the other hand, $15 \% \mathrm{NaOH}$ treated jute yarn showed a good swelling effect.

The tensile strength; Young's modulus and elongation at break of different concentrated alkali treated jute yarn is illustrated in Table 1.

\begin{tabular}{|c|c|c|c|c|}
\hline $\begin{array}{c}\text { SL. } \\
\text { No }\end{array}$ & $\begin{array}{c}\text { Chemical \& } \\
\text { Concentration }\end{array}$ & $\begin{array}{c}\text { Tensile Strength } \\
(\mathrm{MPa})\end{array}$ & $\begin{array}{c}\text { Young's } \\
\text { Modulus } \\
(\mathrm{GPa})\end{array}$ & $\begin{array}{c}\text { Elongation at break } \\
(\%)\end{array}$ \\
\hline 01. & $5 \% \mathrm{NaOH}$ & 511.50 & 16.92 & 1.30 \\
\hline 02. & $10 \% \mathrm{NaOH}$ & 480.36 & 15.89 & 1.23 \\
\hline 03. & $15 \% \mathrm{NaOH}$ & 454.06 & 15.02 & 1.19 \\
\hline 04. & $20 \% \mathrm{NaOH}$ & 422.62 & 13.98 & 1.29 \\
\hline 05 & $10 \% \mathrm{Na}_{2} \mathrm{CO}_{3}$. & 506.06 & 16.74 & 1.33 \\
\hline 06. & Ammonia & 516.94 & 17.10 & \\
\hline
\end{tabular}

Table 1. Illustrated the tensile strength, young's modulus and elongation at break of jute yarn

The table illustrated that the tensile strength of ammonia treated jute yarn is more. Also, the yarn is broken down after $1.33 \%$ of elongation. Ammonia treated jute yarn shows less swelling properties. On the other hand, $15 \% \mathrm{NaOH}$ treated jute yarn shows good swelling properties. By comparing the above properties, we got maximum woolenized effect on $15 \%$ $\mathrm{NaOH}$ treated jute yarn. 


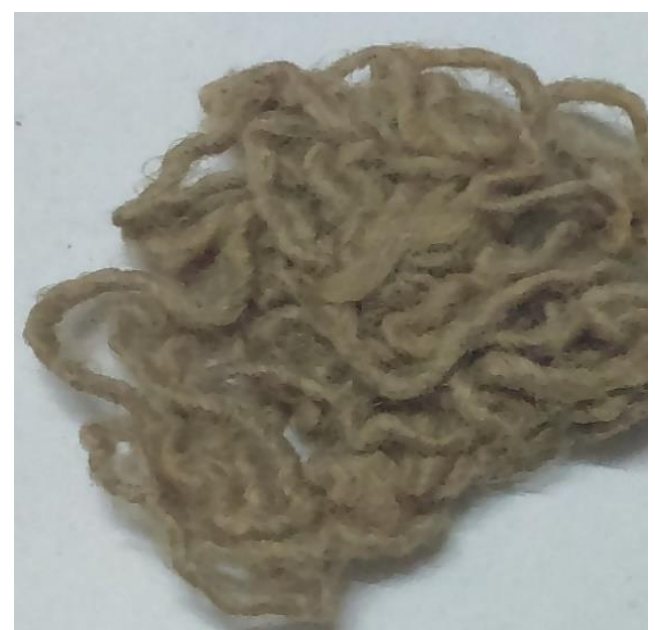

$5 \% \mathrm{NaOH}$ treated jute yarn

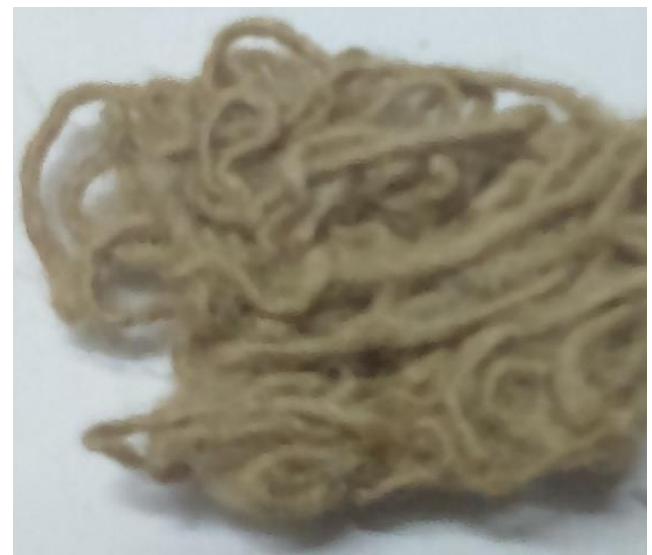

$15 \% \mathrm{NaOH}$ treated jute yarn

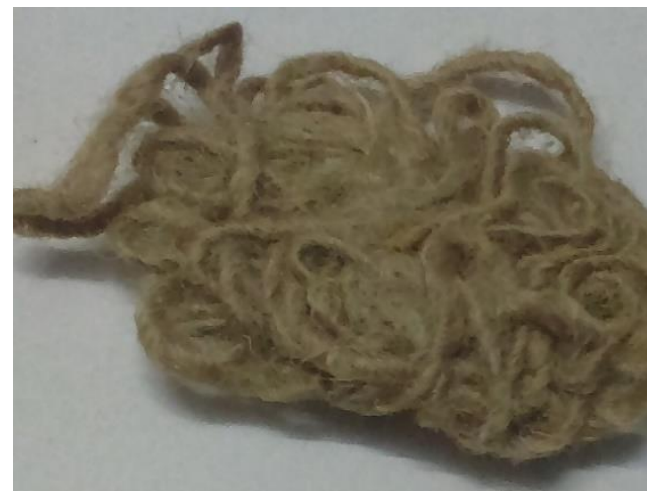

$10 \% \mathrm{Na}_{2} \mathrm{CO}_{3}$ treated jute yarn

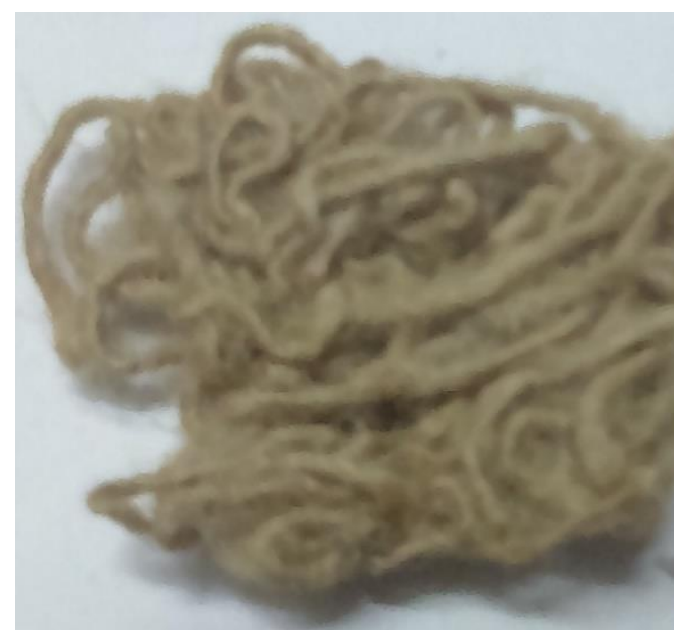

$10 \% \mathrm{NaOH}$ treated jute yarn

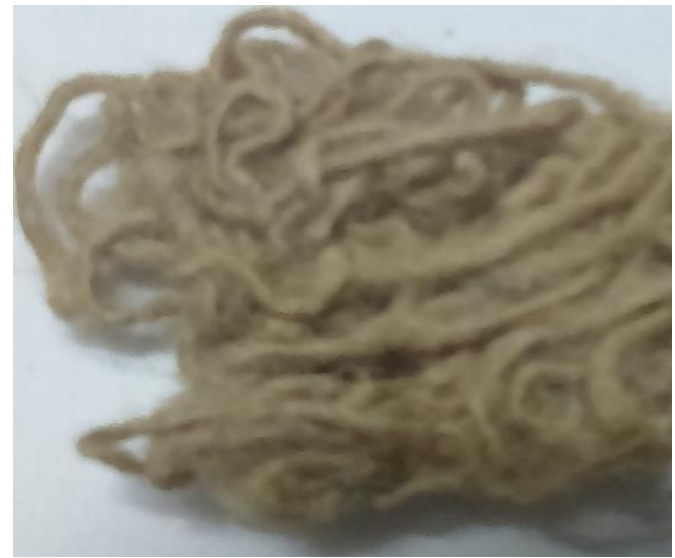

$20 \% \mathrm{NaOH}$ treated jute yarn

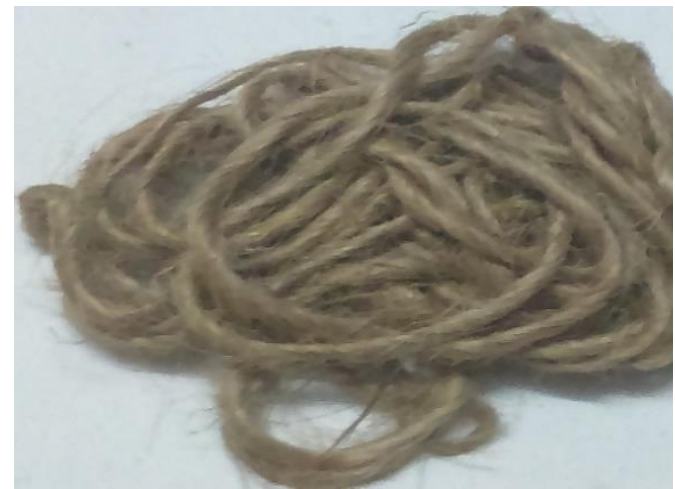

Ammonia treated jute yarn

Figure 5. Treated Jute Yarn by Different Concentration of Different Alkali 


\section{Dyeing}

By dyeing with basic dye, we got different colorful yarn. The appearance of jute yarn is changed.
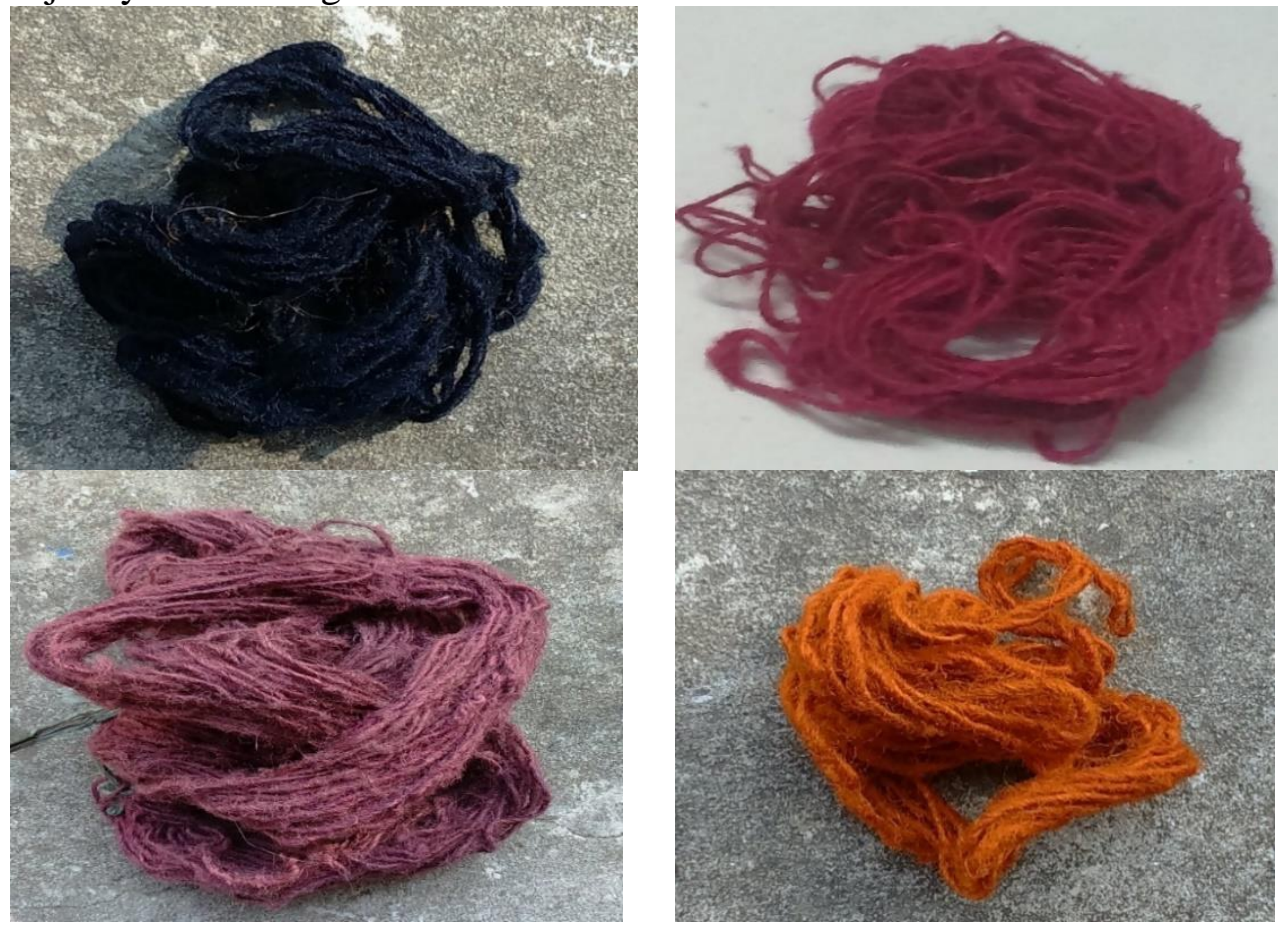

Figure 6. Dyed Jute Yarn

\section{Softening}

After the dyeing of $15 \% \mathrm{NaOH}$ treated jute yarn, softening is done. By softening process, we got softened woolenized jute yarn which is more soft to touch than previous yarn. Here, the stiffness of jute yarn is reduced.

\section{Knitting}

By hand knitting of colorful jute yarn, we got knitted product.

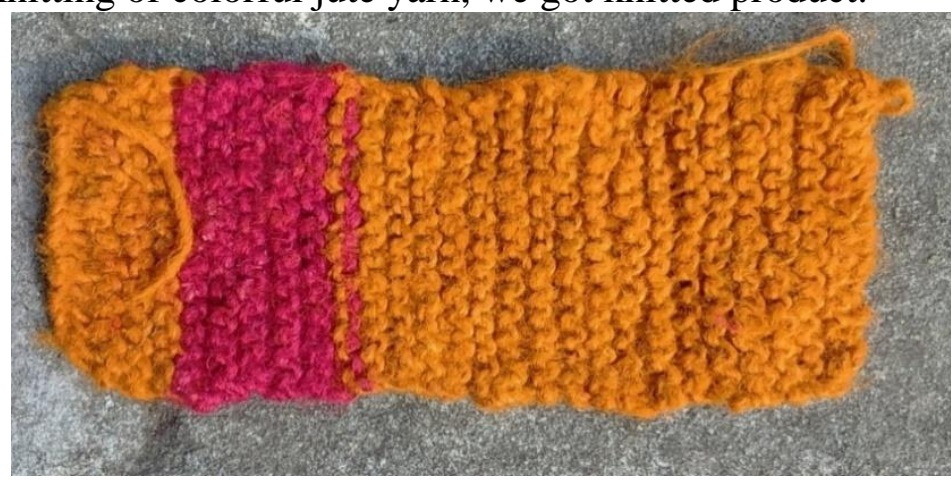

Figure 7. Hand Knitted Jute Fabric 


\section{Finished Products}

From jute fabric, we prepared jute products. The product of woolenized jute fibre is hand bag.

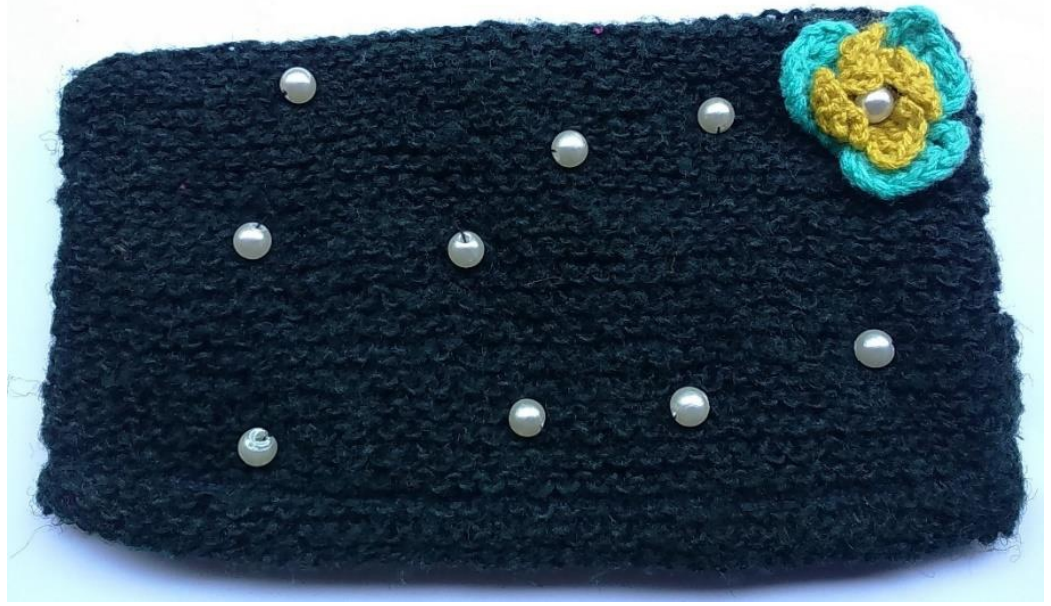

Figure 8. Woolenized Jute Hand Bag

\section{Conclusion and Recommendation}

Global awareness about a pollution free environment is being built up and people in general, are becoming more inclined to the use of natural fibre products. These products are not only environment-friendly but would also serve the intended purpose. The effect of woolenization on jute fibre shows remarkable change in its physical and chemical properties, and the structure of jute was turned nearly into wool fibre. Different concentrations of alkalis show different results in our project work, but finally got better results from $15 \% \mathrm{NaOH}$ treated jute fibre. From this treated fibre, we made woolenized jute product which was environmentally friendly and same as wool products.

\section{Limitation}

- $\quad$ The main limitation of jute was its stiffness and the fibre is coarse compared to wool. It is difficult to make finer uniform yarns.

- $\quad$ Also, jute is more swelled up when the strength of jute yarn was reduced.

\section{Scope}

The price of wool yarn is higher than jute yarn. So, if we replace wool yarn, it will become more beneficial. Again, the cultivation of jute yarn in our country is more. In recent years, the market share of jute yarns has decreased. So, if we introduce it to our world market, we can improve the market share of jute yarn. 
Further research should be carried out on the mixture of woolenized jute fibre with wool fibre which may appear better with woolenized effect.

\section{References:}

1. Andrzej K. Bledzki and Jochen Gassan (1999). [Online]. Available: http://www.sciencedirect.com/.

2. Anup K. Nandi, Utpal Banerjee, \& Debkumar Biswas (2010). "Indian Jute Research Association," [Online]. Available: http://www.ijira.org/.

3. Atkinson A. R.R. Jute (Fibre to Yarn).

4. Bassu G. (1996). "The effect of ambient temperature bleaching of jute fiber with hydrogen peroxide," Indian Journal of Fiber \& Textile Research.

5. Bijay Dhakal (2013). National Institute Of Technology [Online]. Available: http://www.nitt.edu/.

6. Chowdhury N. \& Azd N.K (2009). Chemical Effect Of PhysicoMechanical Properties Of Jute \& Jute-Synthetic Blended (80/20) YARNS, J. Soil. Nature, vol. 3, no. 1, 15 March.

7. Cook J. G. Hand Book of Textile Fibres.

8. Cottle D. International Sheep \& Wool Handbook.

9. Dipa Ray \& Sarkar (2001). "ResearchGate," [Online]. Available: https://www.researchgate.net/publication.

10. Ghose B. \& Dutta A. (1989). "Possibilities for improving the mechanical properties of jute/epoxy composites by alkali treatment of fibres," Composite Science \& Technology, vol. 49. L. V. E.P.G. Gogl, Textile Science.

11. Morton W. E. and Hearle J. Physical Properties of Textile Fibres, 4th, Ed.

12. Menachem Lewin E. M. (1998). Handbook of Fibre Chemistry.

13. Ray S. (2010). Application of Jute fiber. Composites of Science \& Technology, vol. 70, no. 7.

14. Ray P. \& Das B. (2003). "Partial Mercerisation \& Crimp development jute fiber," Wily online library, 11 March.

15. Samanta A. \& Ghose P. (2008). The Spinnability of jute by treating with glycol \& acrylamide. Indian Textiles Book.

16. [Online].

Available: http://nptel.ac.in/courses/116102026/Flash/fig22.jpg.

17. [Online]. Available: http://jpkc.qdu.edu.cn/fzclx/english\%20course/pic/36.JPG.

18. [Online]. Available: http://www.bjri.gov.bd/.

19. [Online]. Available: http://www.bio.cam.ac.uk/hbrec.

20. [Online]. Available: http://www.fiberartsemporium.com/. 